\title{
Variable frequency drive optimization using torque ripple control and self-tuning PI controller with PSO
}

\author{
Mudundi Rekha ${ }^{1}$, Malligunta Kiran Kumar ${ }^{2}$ \\ ${ }^{1}$ Koneru Lakshmaiah Education Foundation, Vaddeswaram, Guntur, Andhra Pradesh, India \\ ${ }^{2}$ Departement of Electrical and Electronics Engineering, Koneru Lakshmaiah Education Foundation, Vaddeswaram, \\ Guntur, Andhra Pradesh, India
}

\begin{abstract}
Article Info
Article history:

Received Apr 27, 2018

Revised Oct 26, 2018

Accepted Nov 18, 2018

\section{Keywords:}

DC-bus-voltage-ripple

Particle swarm optimization

Q-axis average current

Q-axis ripple current

Self-tuning PI controller

Torque ripple control

Variable frequency drive

ABSTRACT

Drive's output power must be restricted for the prevention of stresses over higher components in the input power system while utilizing a three-phase Variable Frequency Drive (VFD) which has powered from a single-phase AC source. To resolve this problem, a novel motor q-axis current (M-QAC) with torque ripple control (TRC) of an induction motor and self-tuning PI controller with particle swarm optimization (STP-PSO) is introduced for mitigating the stress over induction motor by the torque ripple elimination and controlling. The proposed approach has an information related to the stresses of different parts of the VFD which includes the terminal block and the diodes in the input side, DC bus capacitors, torque ripple, harmonics in the current and active performance for sudden changes in the speed and load. The proposed model is simulated in MATLAB/Simulink environment. In this paper the standard dc-bus voltage ripple-based fold- back, $q$-axis average current fold-back and $q$-axis ripple current fold-back methods are utilized for the comparative analysis. Also, the comparative analysis of proposed M-QAC, TRC and STP-PSO methodologies are provided with respect to steady-state values of peak-to-peak dc voltage $\left(\mathrm{V}_{\mathrm{dc}}\right)$, peak-to-peak input current ( $\left.\mathrm{I}_{\mathrm{INPUT}}\right)$, input RMS current $\left(\mathrm{I}_{\mathrm{RMS}}\right)$, motor speed and the output power. Extensive simulated performance show that the STP-PSO obtained superior results over conventional standard dc-bus voltage ripple-based fold-back method, M-QAC and TRC schemes.
\end{abstract}

Copyright $(2019$ Institute of Advanced Engineering and Science. All rights reserved.

\section{Corresponding Author:}

Mudundi Rekha,

Koneru Lakshmaiah Educational Foundation,

Vaddeswaram, Guntur, Andhra Pradesh, India.

Email: rmudundi@gmail.com

\section{INTRODUCTION}

A new trend to adjust the speed of a three-phase induction motor is by using variable frequency drives. By and large, an induction motor can keep running at its evaluated speed when it is associated specifically to the appraised supply voltage. Notwithstanding, numerous applications require variable speed activities. In a large portion of the applications the input power is specifically relative to the 3D square of motor speed. In specific applications like induction motor based divergent pump, a speed diminishment of $20 \%$ outcomes in an energy sparing of around half. The two vital requirements in the present current period are driving and controlling the induction motor effectively. With the new advancements created in the semiconductor manufacture innovation, the size and the cost of semiconductors have gone down, which implies that the end client can supplant an energy wasteful mechanical motor drive and control system utilizing a Variable Frequency Drives (VFD) [1]-[3]. Rustic water system and bar directs in remote areas utilized for extricating oil from profound wells are a portion of the run of the mill applications that require powering up three-phase Variable Frequency Drives (VFDs) from single-phase AC source because of inaccessibility of three-phase power [2]. The VFD controls the motor speed as well as can enhance the 
motor's dynamic and enduring state qualities also. Likewise, the VFD can lessen the system's normal energy utilization. Rustic water system utilized for water pumping and directs utilized for extricating oil from profound wells are a portion of the run of the mill applications that require powering up three-phase (VFDs) from single-phase ac source. In remote areas, three phase ac power may not be accessible.

Numerous VFD producers force confinements on the rating of the VFD for use with a single-phase ac source. Vital concerns while working a three-phase VFD from a single-phase ac source are that the RMS estimation of the input ac is no less than twice that when a three-phase supply is utilized for a given load. The input diodes must deal with the higher current interest for a given load. Likewise, in a diode rectifier with a vast dc transport capacitor, the current streams just when the momentary estimation of the input voltage is higher than the dc transport voltage, the current stream is irregular and has a huge pinnacle when the input is a single-phase ac source. The higher pinnacle current through the rectifier diode causes bothersome warm worry in the diodes and may prompt untimely disappointment. Another issue is that higher input current influences the input ac power terminal squares. Regardless of whether the diodes can deal with the higher current, the terminal pieces may not be evaluated to deal with the higher RMS current constantly. Input current symphonious twisting is additionally high when single-phase input is utilized to power threephase inverters. Higher consonant substance is related with a lower input power factor and poor system efficiency. Single-phase ac supply brings about higher swell voltage over the dc transport. Higher swell voltage means higher swell current through the capacitor and more warming of the capacitor. The inverter is normally derated to deal with the higher capacitor swell current. Thus, there is a need to address every one of these issues.

For this, a non-regenerative circuit is included between the rectifier and inverter to empower three phase VFD use from a single ac supply. When utilizing a three-phase VFD powered from a single-phase ac source, the drive's output power must be restricted to avert higher component stresses in it and in the input power system. At the point when an induction motor in VFD is worked from a control, torque ripple at different frequencies may exist over the working velocity run. It is of significance that the hardware not be worked longer than quickly at a speed where a thunderous condition exists between the torsional system and the electrical system (i.e., the motor electrical torque). It likewise is conceivable that a few speeds inside the working extent may relate to the common mechanical frequencies of the load or support structure and operation other than immediately could be harming to the motor as well as load and ought to be maintained a strategic distance from at those rates.

There are many techniques employed to address the issues faced when single-phase ac supply is used to power three-phase VFDs [4]-[10]. The conventional active boost topology used for powering VFDs has some disadvantages. The main drawback of voltage ripple is overcome by using interleaving of boost converters topology [5]. In [6], a bridgeless rectifier that has high power density employing coupled inductors is discussed. In such topologies, the boost inductor is on the input ac side. However, an important drawback of most bridgeless rectifiers is that they need high-speed fast-recovery diodes in the rectifier circuit, which makes them expensive. In [7], a dc bus midpoint is created using two capacitors in series. One of the phases of the three-phase ac motor is also connected to the dc bus midpoint. The remaining two phases are connected as usual to two of the output phases of a typical output stage of a four-switch H-bridge topology. The topology of [7] is also inherently regenerative, which can be an important advantage in certain applications. The topology discussed in [8] uses the structure which is known as the B4 topology as its base. In [8] modifications to the base topology is suggested by adding extra switches to create three additional interconnection options for the motor windings, known as B4f, B4vf, and B4vfzin. In two of these new variations (B4f and B4vfz), one needs to access the neutral point of the ac motor, which makes them impractical from the industrial application point of view. In addition, the extra switches make the topologies the same cost as a traditional six switch (B6) topology. Various versions of the base topology have been well exploited in [9] to result in interesting low-cost topologies. In all the topologies discussed in [7]-[9], one or more motor windings are connected to the input single phase ac supply. The third phase is controlled in a pulse width-modulated manner to generate positive sequence voltages. Common-mode voltage and EMI conducted back into the source remain the major issues with the added drawback of requiring larger voltage ratings for the switches in the topology. In numerous country regions, because of the inaccessibility of three phase ac power, three-phase VFDs are frequently required to work from a single-phase ac source. The input current streaming into a three-phase VFD working from a single-phase ac source is no less than two times more prominent than that streaming with a three-phase ac source; thusly, there are sure issues that must be tended to when utilizing three phase drives with a single-phase ac source. The primary issue is capacitors overheating because of higher ripple currents. The second issue is surpassing the peak current rating of the input diodes. Lamentably, for a few systems, the diode's peak current rating could be lower than the ripple current limit of the dc bus capacitor. For such systems, if the output power is restricted by utilizing just the dc-bus voltage-ripple based frequency crease back strategy, it is conceivable that the diode rectifiers get 
focused. This will lessen the mean time between failures (MTBF) for the diodes. Also, one must be worried about the constant current rating of the input diodes and input terminal pieces. By and large, the diodes might have the capacity to deal with the higher estimations of the root-mean-square (RMS) current, yet the terminal pieces may not be evaluated to deal with the peak current on a nonstop premise. To beat these issues, numerous VFD producers utilize three methods for managing three-phase VFDs powered from single-phase ac sources: 1) derate VFDs, 2) extra equipment, and 3) utilizing control calculations to limit the part stresses in the VFD.

\subsection{Derate VFD's}

Most of the issues mentioned in the preceding section are addressed by severely derating the VFDs for single phase applications. In the VFD, the derating scheme have confidence on the dc-bus capacitor ripple-current rating. It's very simple and easy to develop as it doesn't require any advancement in the hardware. In many situations, the control algorithm is much similar with the traditional phase-loss monitoring and protection built in. Still, it should be severely derated to obtain the most reliable performance. Recent developments in the hardware-based techniques have addressed this issue [4]-[12]. A novel, low-cost hardware technique [4] that does not need any VFD modification is discussed next.

\subsection{Additional hardware-based topology to overcome derating of VFDs}

The fundamental guideline of the topology proposed in [11] is to store energy in an outside inductor and recover it at a suitable moment of time. A bidirectional switch is utilized for putting away and recovering energy from the inductor, and its current rating is under $35 \%$ of the appraised current of the air conditioner to dc rectifier. The topology likewise loans itself for simple joining with the VFD. The topology proposed in [11] is appeared in Figure 1. One essential downside of this topology is that the lift inductor is expansive in estimate $(0.2$ p. u.) since the charging cycle happens just twice every input cycle. Be that as it may, the utilization of extra equipment adds to the system's cost, size, and unwavering quality. Certain controlcalculation methods can be utilized, in conjunction with the derate choice, to enhance the performance and unwavering quality of the VFDs powered from a single-phase ac source.

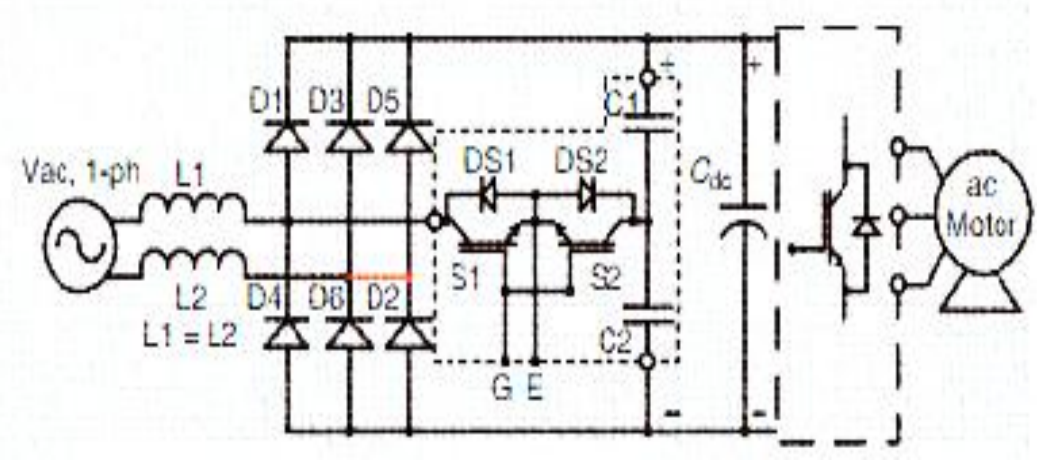

Figure 1. Non-regenerative single-phase active front-end circuit

\subsection{Frequency fold-back based on voltage ripple across de bus capacitor}

In the frequency overlay back strategy, which is based on sensing the ripple voltage over the dc bus capacitors as depicted in [13], the essential introduce is that the dc-bus ripple-current amplitude can be anticipated by estimating the ripple voltage over the dc bus capacitor. Since a dc bus capacitor current can't be specifically estimated, recommends utilizing the dc-bus capacitor-voltage ripple. The capacitor-ripple current is specifically corresponding to the dc-bus capacitor-voltage ripple. The ripple over the dc bus voltage is estimated, and the drive output frequency is diminished in like manner to confine the output power and, all, as far as possible the ripple current through the capacitor. Despite the fact that this technique has been received and regularly adjusted [14] in the business since it appears to confine the power rating of threephase VFDs that are working from single-phase ac sources, it doesn't represent the burdens that happen in different parts of the VFD, particularly because of the diode crest current and the RMS current that gone through the input terminals. Even though the frequency crease back in view of the dc-bus voltage-ripple technique is straightforward and simple to utilize; certain issues have been seen in the field. The most essential one is that the dc-bus capacitor-ripple-voltage resistance level might be higher than the crest to-crest 
current-ripple-taking care of ability of input-diode rectifiers or the RMS current limit of the input terminal pieces, particularly in littler measured VFDs. While the calculation may decrease the output frequency and consequently restrain the output power, it might even now be higher than what the input diodes can deal with on a nonstop premise. Besides, the frequency fold-back in view of the dc-bus voltage-ripple strategy isn't an immediate control technique.

The dc-bus voltage-ripple may not mirror the genuine condition of the capacitor. On the off chance that capacitance has decayed, at that point the normal voltage held can be low while the ripple could in any case be inside as far as possible. A lower dc bus voltage will cause higher input current for a given load level and can unfavorably influence the input diodes and terminal pieces. A comparative succession of occasions can happen if the single-phase ac source nourishing the drive is a feeble ac source. Consequently, the dc-bus voltage ripple isn't adequately solid since it disregards outer components, for example, input voltage, source impedance, and powerful capacitance, which can influence the load level at which fold-back happens, which can prompt poor VFD use.

To address these issues, numerous VFD makers derate the drive. Commonly, considering the dc-bus voltage ripple [15], the output frequency of the drive is constrained with the goal that the capacitors are not overemphasized. This technique does not consider the stresses in other VFD components, particularly the input diodes and terminal pieces. Recently, [16] proposed a method for protecting the drive, which has information that is related to the various parts stresses in VFD, which includes the terminal block and the diodes at the input side and the dc bus capacitors. By mitigating the output frequency, the output power can be restricted based on the mean and ripple amplitudes of the QAC instead of the dc-bus-voltage ripple. This method does not consider the stress over AC motor i.e., controlling of torque ripples occurrence in motor when it operates at various frequencies over different range of speed. In this proposal, authors introduced a motor q-axis current with torque ripple control (MQAC-TRC) of an induction motor and self-tuning PI controller with particle swarm optimization (STP-PSO) for mitigating the stress over induction motor by the elimination and controlling the torque ripple, current harmonics and active performance for sudden changes in speed and load.

The novel contributions of this work can be summarized as follows:

a) Novel use of MQAC-TRC and STP-PSO for optimizing the VFD's by mitigatin the stress over the induction motor, various components and sudden changes in speed and load. This combo has not been used for the VFD applications before, according to the best knowledge of the authors.

b) Only few researchers have presented the MQAC [16] and dc-bus voltage ripple [15] to enhance the life time of VFD's by eliminating the stress over various components. However, the authors in [15] and [16] doesn't consider the stress over induction motor.

c) A fully new framework is proposed for further mitigation of the stress over the various components and induction motor using MQAC-TRC and STP-PSO for mitigating the limitations of the works presneetd in [15] and [16].

The rest of the paper is organized as follows: The proposed control strategy is described in Section 2. Section 3 explains the results and comparative evaluations against literature. Finally, Section 4 concludes the paper followed by references.

\section{PROPOSED CONTROL MODEL}

The proposed method advocates the use of a variable that has information on component stresses and is directly measured instead of estimated. The parameter that has these details along with information on output load conditions is the torque-producing, or $q$-axis, component of the output current that represents the active current of the motor. In any VFD, for protection and control purpose, there is a need of continuous measurement of the output current. By utilizing the output current, component $q$-axis is evaluated on a continual basis and a controlled response will be offered to load enhancement. Therefore, stress in the components of VFD gets increased, especially when it is powered from a single-phase ac source. There are two aspects of this current: 1) the average value of $q$-axis current (IQ-AvG) and 2) the peak-to-peak ripple value of $q$-axis current (IQ-RIPPLE). The value of the $q$-axis average current may be utilized for restricting the VFD's output power, which leads to the reduction of stresses over the input diodes as well as the terminal blocks, especially in low-power VFDs. By the utilization of peak-to-peak $q$-axis ripple current, we can restrict the ripple current via dc-bus capacitors. This dual-bifurcate scheme helps for VFD's optimization for the utilization with a single-phase ac source. The proposed technique advocates the utilization of a variable that has data on component stresses and is straightforwardly estimated rather than assessed. The parameter that has these points of interest alongside data on output load conditions is the torque-delivering, or q-axis, component of the output current that speaks to the dynamic current of the motor. In any VFD, the output current is straightforwardly and consistently estimated for control and assurance purposes. The q-axis part is 
gotten from the output current on a persistent premise and offers a controlled reaction to an expansion in stack and, henceforth, an expansion in stresses in the components of a VFD, particularly when it is powered from a single-phase ac source. There are two parts of this current: 1) the average estimation of q-axis current (IQ-AVG) and 2) the peak-to-peak ripple estimation of q-axis current (IQ-RIPPLE). The average estimation of the qaxis current might be utilized for constraining the output power of the VFD. This will restrict the weights on the input diodes and the warm stresses in the input terminal squares, particularly in low-power VFDs. The peak-to-peak q-axis ripple-current esteem is utilized to restrain the ripple current through the dc bus capacitors. This double pronged approach helps in enhancing a given VFD rating for use with a single-phase ac source.

The flowchart for the proposed M-QAC is appeared in Figure 2. The control calculation has two pi controllers. The main controller directs the most extreme output q-axis average current (IQ-AVG), which relies upon the drive size and its voltage rating. The second controller directs the q-axis ripple-current (IQ-RIPPLE) adequacy. The two controllers work autonomously, yet when all is said in done, the q-axis average current controller has higher need. Contingent upon the relative rating of the insistent peak diode current and the ripple-current limit of the dc bus capacitors, a higher need can be attributed to either the q-axis normal current controller or the q-axis ripple-current controller by modifying the activation and direction levels for either controller.

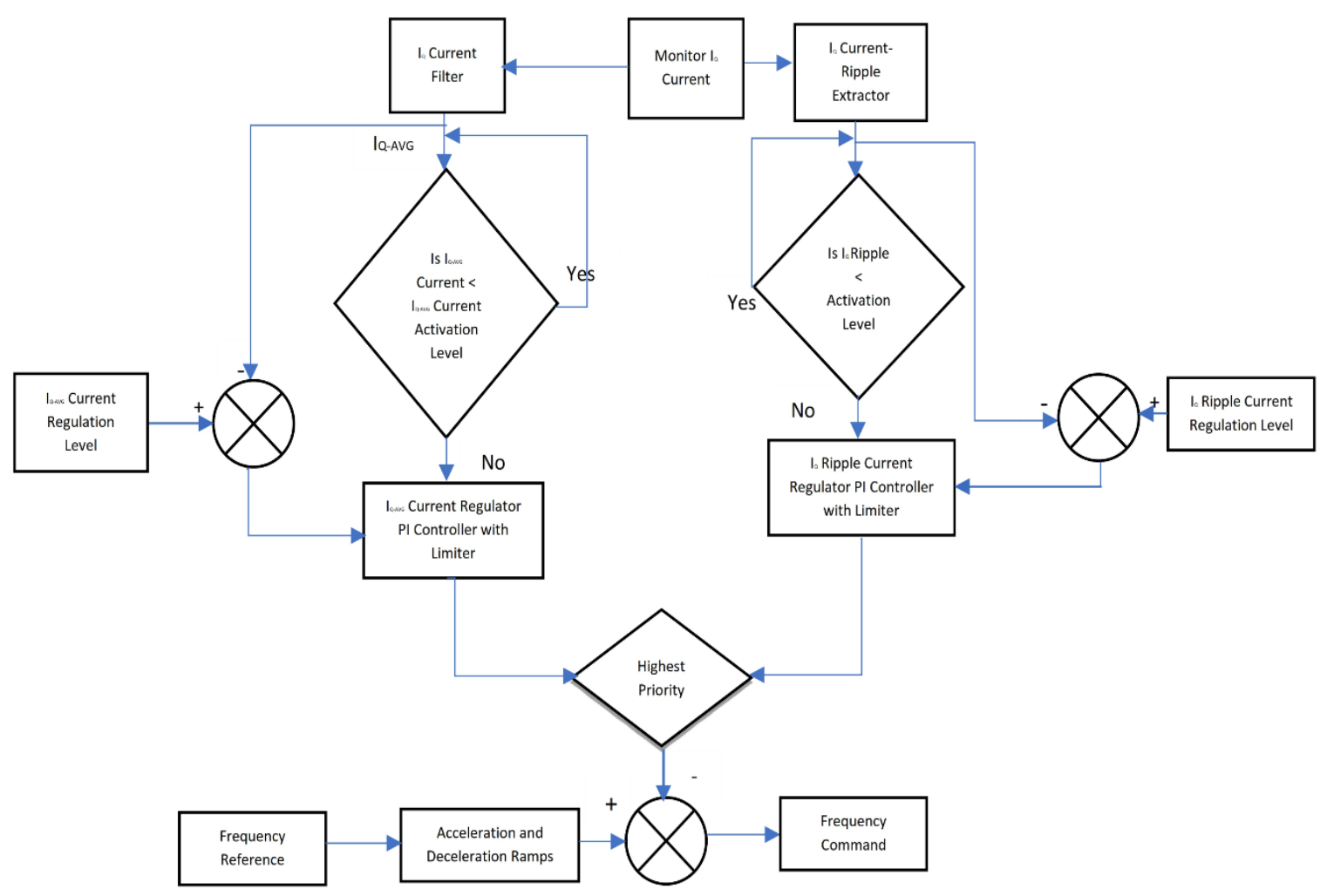

Figure 2. Proposed M-QAC block diagram

\section{1. q-axis average ( $\left.\mathrm{I}_{\mathrm{Q}-\mathrm{AVG}}\right)$-current-based fold-back method}

In the q-axis average current controller, the drive's output q-axis average current is contrasted and the output average current actuation level set in a query table. If the deliberate esteem is higher than the actuation level, at that point the pi controller of q-axis average current regulator is initiated. The output of the pi controller is negative and dependably subtracts from the frequency reference to create a lower frequency charge. On the off chance that the output q-axis current is reliably higher than the direction level, this pi controller slowly soaks to the base output frequency, the estimation of which can be set by the client. If the drive works at this insignificant output frequency for longer than a prearranged settled measure of time, it can be made to blame out at the carefulness of the client. Be that as it may, if the load works perfectly at the decreased frequency without requesting a higher current, at that point the calculation keeps up an ideal frequency to control the output current at the set point esteem or direction level. 


\section{2. $q$-axis ripple ( $\left.\mathrm{I}_{\mathrm{Q}-\mathrm{RIPPLE}}\right)$ - current-based fold-back method}

In the q-axis ripple-current controller, the amplitude is contrasted and the controller enactment level set in another query table. If the deliberate esteem is higher than the enactment level, at that point the ripplecurrent controller is initiated, and the controller directs the output frequency such that the q-axis current ripple settles down to the control level. The output of the pi controller is negative and dependably subtracts from the frequency reference to produce a lower frequency charge. Once the ripple controller is dynamic, it can be incapacitated just if the q-axis current ripple falls beneath the deactivation level. This guarantees the output of the pi controller is operational just inside the enactment and deactivation levels, along these lines forestalling high output frequency swings that can bring about high input-diode current and high capacitor current.

\subsection{Torque ripple control}

Proposed flow chart for torque ripple control is depicted in Figure 3. Line current ripple in a PWM inverter is caused by the momentary mistake between the connected and reference voltages. Since the error voltage vector sees the motor as its aggregate spillage inductance, the current ripple vector is corresponding to the time basic of the error voltage vector. The current ripple vector can be settled along the d-and q-axes, which are the reference axes of a synchronously spinning reference outline.

The current ripple along the $\mathrm{d}$-and $\mathrm{q}$-axes, where the amounts $\mathrm{Q}_{1}, \mathrm{Q}_{\mathrm{z}}$, and $\mathrm{D}$ are defined as follows:

$$
\begin{aligned}
& Q_{1}=\frac{V_{d c}}{l}\left[\cos \alpha-V_{r e f}\right] T_{1} \\
& Q_{Z}=-\frac{V_{d c} V_{d c} T_{Z}}{l} \\
& D=\frac{V_{d c} \sin (\alpha) T_{1}}{l}
\end{aligned}
$$

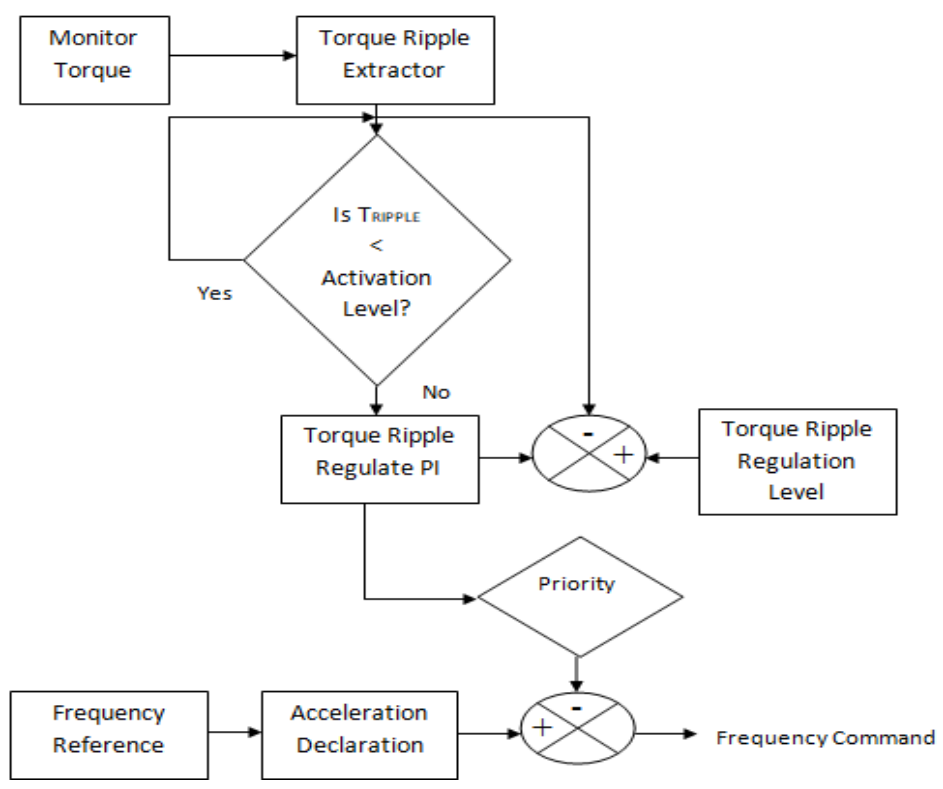

Figure 3. Proposed TRC flow chart

Where Vdc is the dc bus voltage and 1 are the aggregate spillage inductance of the motor. Since the voltage reference vector is lined up with the q-axis and the stator protection drop is irrelevant, there is a consistent flux only along the d-axis. This relentless flux associates with the ripple current along the q-axis to create the ripple torque. Thus, the torque ripple is essentially free of the d-axis current ripple (since there is no relentless flux along the q-axis), while being relative to the q-axis current ripple.

\subsection{Relation between $I_{Q-\text {-ripple }}$ and $T R C$}

The q-axis ripple-current controller is appeared in real life. Here, $\mathrm{I}_{\mathrm{Q}-\text {-ripple}}$-direction is the reasonable estimation of the q-axis ripple current, which is resolved in light of the ripple-dealing with limit of the dc bus

Variable frequency drive optimization using torque ripple control and self-tuning ... (Mudundi Rekha) 
capacitors and the peak current rating of the rectifier diode. $\mathrm{I}_{\mathrm{Q}-\text { ripple }}$-activation represents the level (somewhat higher than the direction level) above which the q-axis ripple-current pi controller is enacted. $\mathrm{I}_{\mathrm{Q}-\text { ripple }^{-}}$ deactivation represents the level (any sheltered an incentive underneath the direction level) below which the $\mathrm{q}$-axis ripple-current pi controller is deactivated. These levels additionally go about as a hysteresis band for ripple current control to avert high output frequency swings. Here, the torque ripple apparently increases, conceivably because of single-phase activity. As the $\mathrm{I}_{\mathrm{Q} \text {-ripple }}$ current esteem increments past the initiation level for the q-axis ripple pi controller, the controller is actuated, and the output frequency is directed to keep up

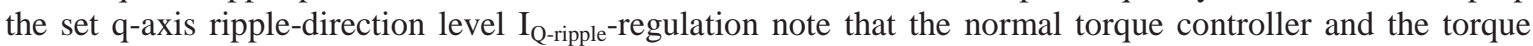
ripple controller act freely. In our illustration, the normal torque controller has a higher need over the torque ripple controller, and if the previous is enacted, at that point the lessening in output frequency and, subsequently, torque is considerably quicker and happens with a more noteworthy advance size. Accordingly, by directing both the normal and the ripple-current controllers with torque ripple controlling, ideal usage of the VFD can be accomplished when associated with a single-phase ac or an uneven three-phase ac source, which can act as a pseudo-single-phase source when the awkwardness increases. The part pushes talked about in this article relate to the low-frequency $(100$ or $120 \mathrm{~Hz})$ ripple. Exchanging the frequency ripple in the dc bus capacitor is the same as the ripple amid three-phase operation for a given working burden condition. Additionally, the q-axis current data is gotten after it is gone through a computerized channel that rejects the exchanging frequency components of the q-axis current. In this manner, the impact of exchanging frequency on q-axis current ripple is irrelevant. For a transition debilitating activity or for an operation above base speed, the torque is diminished to keep the power consistent. As the torque descends, the weight on the drive components is diminished normally.

\subsection{STP-PSO frame work}

PSO is instated with a gathering of arbitrary particles (arrangements) and after that scans for optima by refreshing generations. In each emphasis, every particle is refreshed by following two "best" qualities. The first is the best arrangement (wellness) it has accomplished up until now. (The wellness esteem is likewise put away.) This esteem is called $\mathrm{p}_{\text {best }}$. Another "best" esteem that is followed by the particle swarm optimizer is the best esteem, acquired so far by any particle in the population. This best esteem is a worldwide best and called $g_{\text {best }}$. At the point when a particle removes a portion of the population as its topological neighbours, the best esteem is a nearby best and is called lbest. After finding the two best esteems, the particle refreshes its velocity and positions with following equation.

$$
\begin{aligned}
& v[]=v[]+c_{1} * \operatorname{rand}() *\left(p_{\text {best }}[]-\operatorname{present}[]\right)+c_{2} * \operatorname{rand}() *\left(g_{\text {best }}[]-\text { present }[]\right) \\
& \operatorname{present}[]=\text { present }[]+v[]
\end{aligned}
$$

$\mathrm{v}[]$ is the velocity of the particle, present[] denotes the current particle (solution). $\mathrm{p}_{\text {best }}[]$ and $\mathrm{g}_{\mathrm{best}}[]$ are defined as stated before. rand () is a random number between $(0,1) . c_{1}$ and $c_{2}$ are learning factors. usually $\mathrm{c}_{1}=\mathrm{c}_{2}=2$.

The pseudo code of the procedure is as follows:

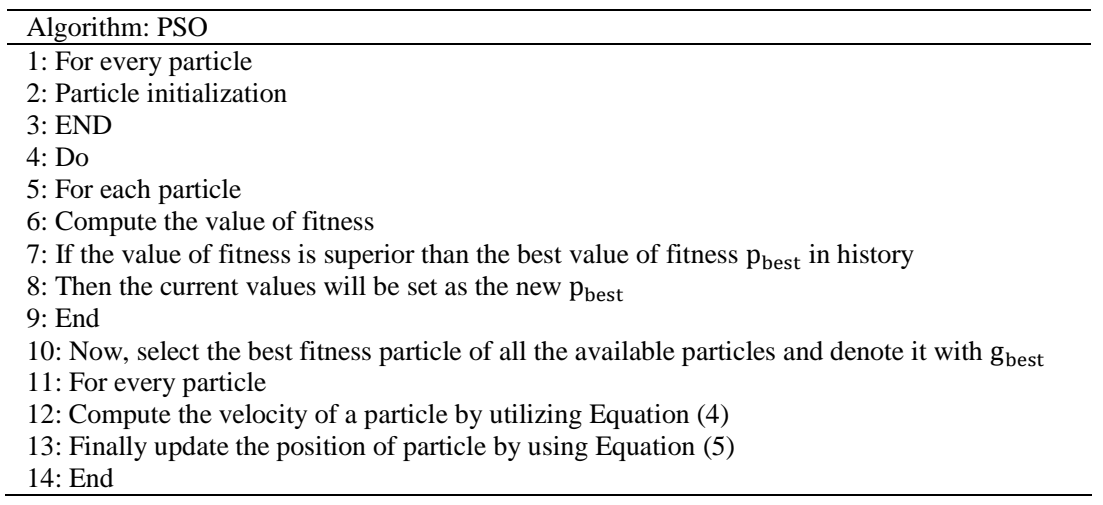

While most extreme cycles or least error criteria aren't achieved, particles' speeds on each measurement are clipped to a greatest velocity Vmax. If the total of increasing speeds would make the velocity on that measurement surpass Vmax, which is a parameter indicated by the client. At that point the velocity on that measurement is restricted to Vmax. 
There are relatively few parameters should be tuned in PSO. Here is a rundown of the parameters and their common esteems.

a) The range of the particles is about 20 - 40. Ideally, most of the issues will be solved by maximum of 10 particles. One can try up to 100 or 200 particles depending on their applications.

b) Particles dimension: It is influenced by the issue to be optimized.

c) Particles range: This is also influenced by the problem that must be optimized, different ranges can be set for the various particle dimensions.

d) Vmax: it's a maximum deviation that a particle can take during an iteration. Generally, the range of Vmax can be set as for example, the particle (x1, x2, x3) X1 belongs [-10, 10], then Vmax $=20$.

e) Learning factors: $\mathrm{c} 1$ and c2 typically equivalent to 2. Be that as it may, different settings were additionally utilized as a part of various papers. However, as a rule c1 equivalents to c2 and ranges from $[0,4]$.

f) The stop condition: the maximum number of iterations the PSO execute and the minimum error requirement. For example, for ANN training in previous section, we can set the minimum error requirement is one mis-classified pattern. The maximum number of iterations is set to 2000. This stop condition depends on the problem to be.

g) The most extreme number of iterations, the PSO execute and the base error necessity. For instance, for ANN preparing in past section, we can set the base error necessity is one mis-ordered example. The most extreme number of cycles is set to 2000. This stop condition relies upon the issue to be.

\section{RESULTS AND ANALYSIS}

In this section, simulation tests were conducted on a frictional load operated from a 10-hp, 230-v, and three-phase VFD powered from a single-phase ac source. Field data were collected from a practical pumping application that used a three-phase 230v, 0.75-hp VFD powered from a single-phase ac supply. The details of the setup for both cases are given in Table 1. We compared our proposed schemes with the M-QAC [16] and classical dc-bus-voltage ripple-based fold-back method [15]. The results obtained with a period of $50 \mathrm{~s}$ by traditional dc-bus voltage ripple-based method is demonstrated in Figure 4, the results include the dc-bus voltage, output power, output frequency and the input current. The time on $\mathrm{x}$-axis includes three slots names as first start-up period, second, loading time and finally fold-back period.

Table 1. Simulation Parameter Values of Motor and VFD Utilized in Experiments

\begin{tabular}{|c|c|c|c|c|c|}
\hline & Rated Power & Rated Current & Rated Voltage & Rated Speed & One-Phase Rating \\
\hline \multicolumn{6}{|c|}{ Pumping Application } \\
\hline Three-Phase Motor & $0.5 \mathrm{hp}$ & $2.1 \mathrm{~A}$ & $200-230 \mathrm{Vac}$ & $3.450 \mathrm{r} / \mathrm{min}$ & N/A \\
\hline Three-Phase VFD & $0.75 \mathrm{hp}$ & $3.5 \mathrm{~A}$ (out) & $200-240 \mathrm{Vac}$ & $1.5-400 \mathrm{~Hz}$ & $0.33 \mathrm{hp}$ \\
\hline \multicolumn{6}{|c|}{ Fractional Load } \\
\hline Three-Phase Motor & $7.6 \mathrm{hp}$ & $19 \mathrm{~A}$ & $200-230 \mathrm{Vac}$ & $1.765 \mathrm{r} / \mathrm{min}$ & N/A \\
\hline Three-Phase VFD & $10 \mathrm{hp}$ & $30 \mathrm{~A}$ (out) & $200-240 \mathrm{Vac}$ & $1.5-400 \mathrm{~Hz}$ & $4.3 \mathrm{hp}$ \\
\hline
\end{tabular}

During time interval $0 \mathrm{~s}$ to $20 \mathrm{~s}$, the drive is loaded up to a value of its rated single-phase rating. fter that it's slightly higher than its rated single-phase rating. As the output power enhances, the output frequency obtains $60 \mathrm{~Hz}$, which is a maximum level of frequency range, and there is an enhancement in the input current then the dc-bus-voltage ripple value overheads it's set value, this will switch the function of frequency fold-back, and results in mitigation of the output frequency after 30s as depicted in Figure 4. Still, the error value is smaller between the specified and actual ripple voltage, and so mitigation rate of the frequency is gradual. The example shown here suggests that there is no sufficient information about the load conditions of the output in the dc bus-voltage ripple method. Hence, this method is not suitable for limiting the input peak current during the frequency fold-back. 


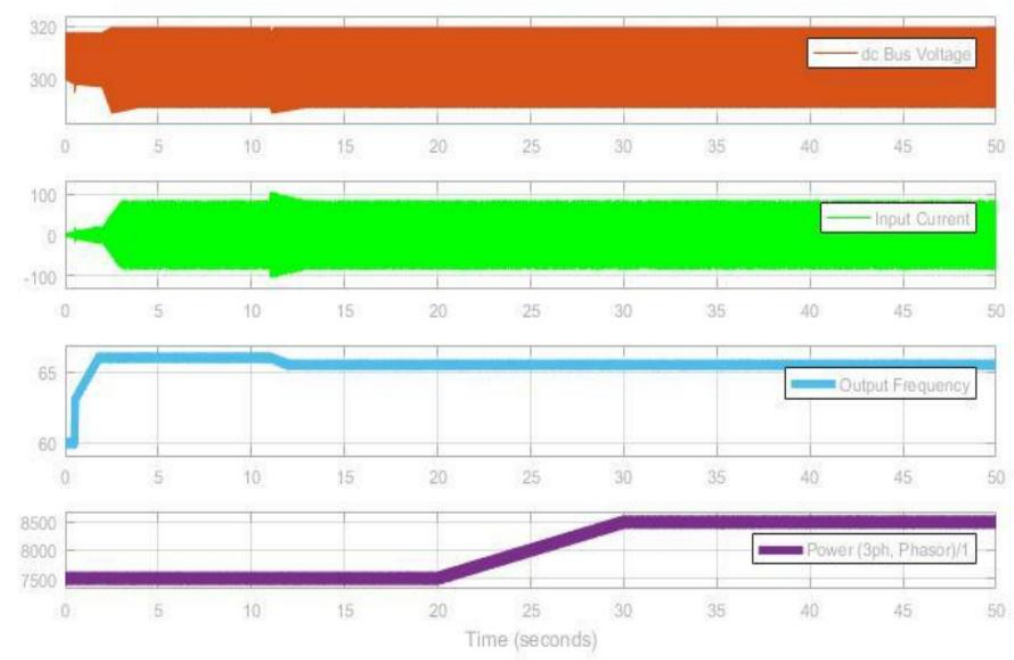

Figure 4. Test results for the dc bus voltage ripple-based frequency fold-back process [15]. Time scale $5 \mathrm{sec} / \mathrm{div}$

Figure 5 depict that the M-QAC based frequency fold-back scheme like the results provided in Figure 4. During time interval 0 s to $17.45 \mathrm{~s}$, the drive loaded up to a value of its rated single-phase rating. During interval $17.45 \mathrm{~s}$ to $21.77 \mathrm{~s}$, the load gets increased which lead to the capacitor-ripple current increment and there by enhances the $q$-axis ripple current. Since the evaluated value of ripple-current is beyond the value of set point, then the activation of pi controller for the $q$-axis current-ripple regulator will be done, this mitigates the output frequency and regulates the output power as seen from time interval 22s. Like the previous case, when the output power is increased to the value at the start of, the $q$-axis average-current regulator detects the increase in current and acts to reduce the output frequency. The regulator saturates to a minimum value since the error is large. Output power, input peak current, and dc-bus-ripple voltage are within specified values at the minimum frequency. Figure 4 and 5 simulations have done with the values of dc Bus Voltage (50 V/div) Input Current (100 A/div) Output Frequency (0.5 V/div) $10 \mathrm{~V}=60 \mathrm{~Hz}$ and Output Power (1 V/div) $1 \mathrm{~V}=7.5 \mathrm{~kW}$

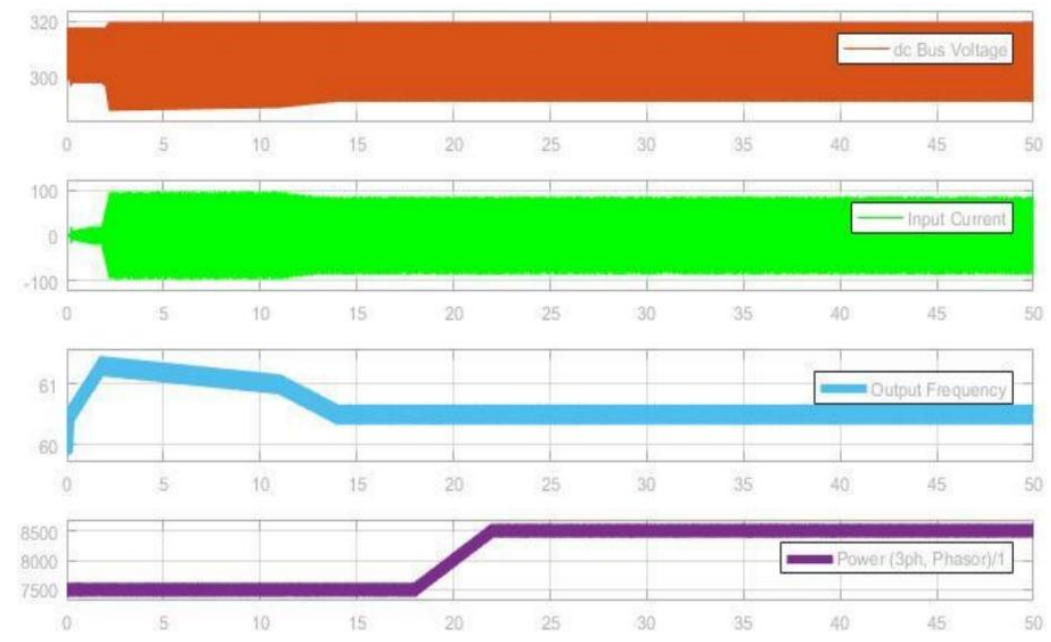

Figure 5. Test results for the q-Axis Current based frequency fold-back process [16]. Time scale 5sec/div

\subsection{Field test data (pump load)}

Field test data were collected for a pump application driven by a $0.75-\mathrm{hp}$, three-phase VFD powered from a single-phase ac source. The single-phase rating of the VFD is $0.33 \mathrm{hp}$. The result for the dc-bus- 
voltage- ripple-based frequency fold-back method and the proposed fold-back method are given in Figures 6 and 8 , respectively. The test results are given in Table 2 .

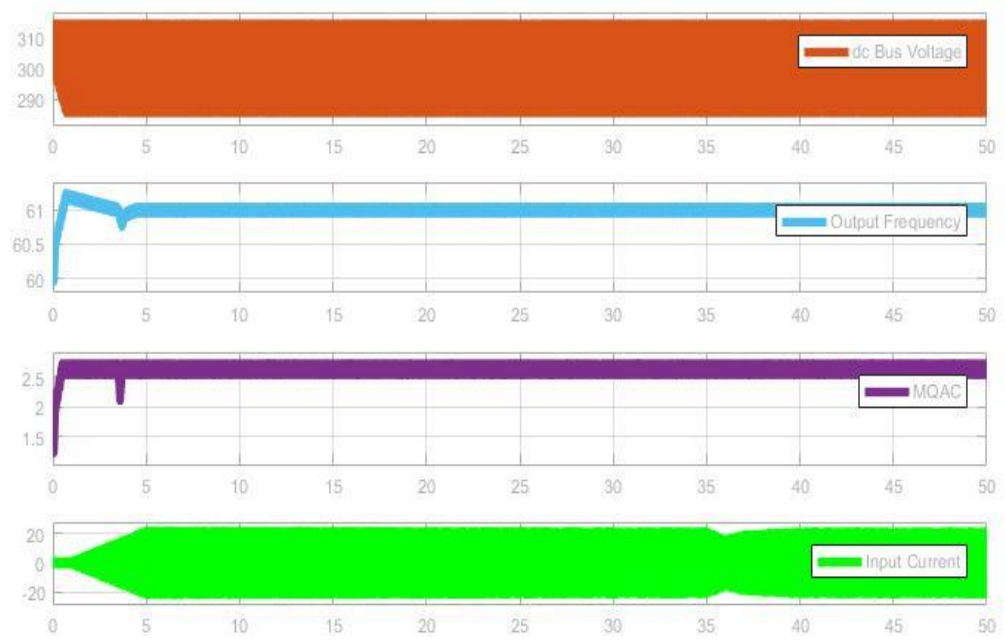

Figure 6. The traditional method that relies only on maintaining allowable dc bus voltage ripple [15] with time scale $5 \mathrm{sec} / \mathrm{div}$

In Figure 6, when the VFD reaches its commanded output frequency, the fold-back process is triggered since the controller registers a dc bus ripple that exceeds the set value. The output frequency reduces gradually until the dc-bus-voltage ripple reaches its specified value. After this point, there is no further decrease in output frequency and, hence, output load. The steady-state output power is $0.47 \mathrm{hp}$, which is higher than the single-phase rating of the VFD $(0.33 \mathrm{hp})$. This discloses that there is no correlation between output power and the dc bus ripple in many VFDs. There will also an enhancement in the diode's peak current due to the output power enlargement, which can mitigate the MTBF for the input rectifiers. The results obtained by M-QAC based frequency fold-back scheme is depicted in Figure 7(a) and Figure 8(b) with $q$-axis ripple-current controller and average-current controller respectively.

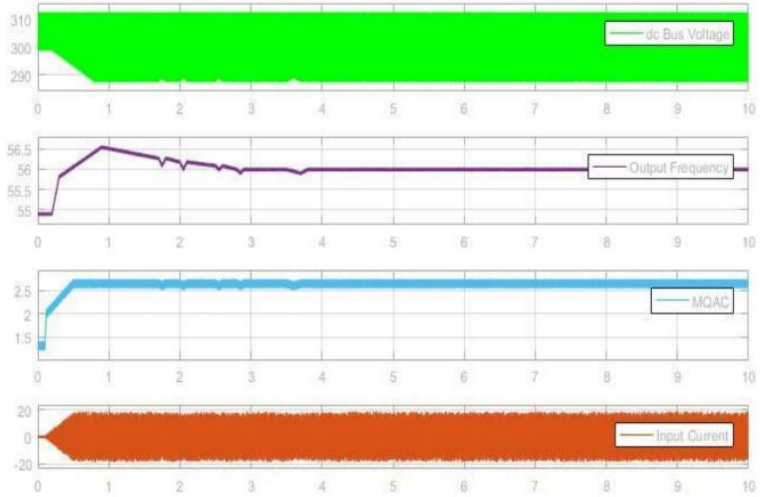

(a)

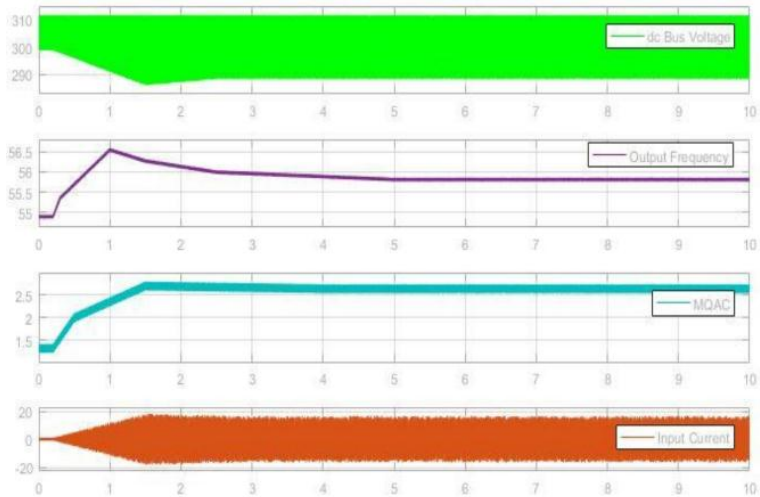

(b)

Figure 7. Test results of proposed q-axis current method for frequency fold-back [16] (a) IQ-Ripple current method with $10 \mathrm{sec}$ (b) IQ-Average current method with $10 \mathrm{sec}$

Triggering of fold-back process will occur once VFD achieves its commanded output frequency since the value of $q$-axis ripple-current is greater than the controller's activation level. As soon as the controller is switched, it oscillates for a brief period, but the oscillations are consisted within the formation of hysteresis band done by the activation and deactivation levels those are defined by users. The output

Variable frequency drive optimization using torque ripple control and self-tuning ... (Mudundi Rekha) 
frequency gets reduced step-by-step until the output power and the dc bus capacitor are at their defined values. There onwards the output frequency regulated at the level of regulation by the controller, that results in an output power of $0.37 \mathrm{hp}$, which is near to the desired value of $0.33 \mathrm{hp}$. The same analysis will be done with the results demonstrated in Figure 7(b). In both the cases ( $q$-axis ripple current and average current controllers), one controller is in active state then automatically the other one gets disabled. Triggering of fold-back process will occur once VFD achieves its commanded output frequency since the value of $q$-axis average-current is greater than the controller's activation level.
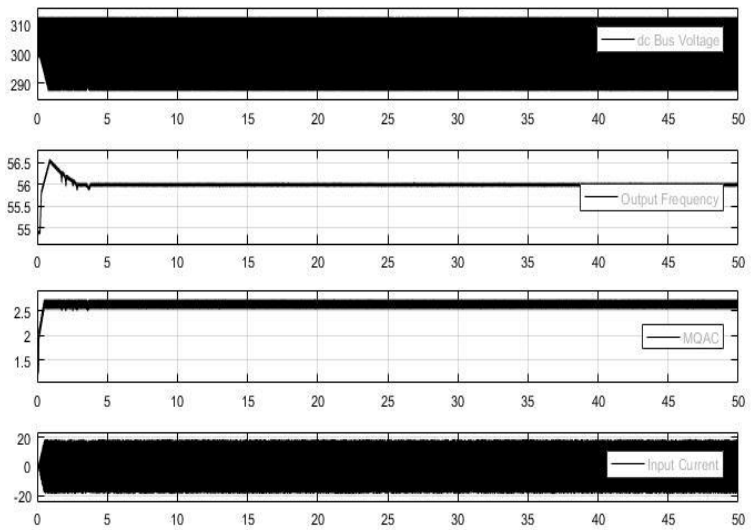

(a)
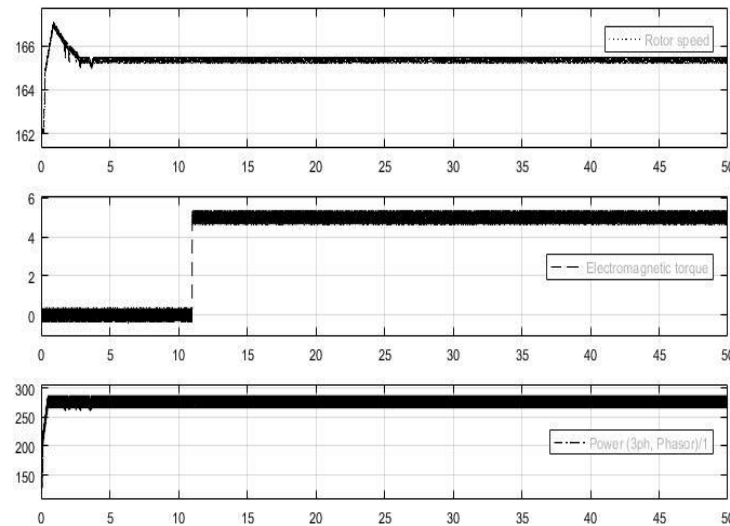

(b)

Figure 8. Test results of proposed q-axis current method for frequency fold-back [16] IQ-Ripple current method with 50sec (a) output frequency and MQAC (b) speed and torque control

Once a secure value of operation has been attained, the output frequency regulated by the controller to approximate that value for the assurance of zero steady-state error. The output power is around $0.31 \mathrm{hp}$ that is within the range of drive's single-phase rating in this case. Figure 8 shows that the performance analysis of IQ-Ripple current method for $5 \mathrm{sec}$ time period, in which we can observe that the dc bus voltage contains ripples when the voltage has been converted from AC to DC, this voltage will be given as an input with q-axis current to the drive after converting into AC again then there will be some distortions in input current as well as the output frequency. Rotor speed and three phase output power depends on input current as well as output frequency.
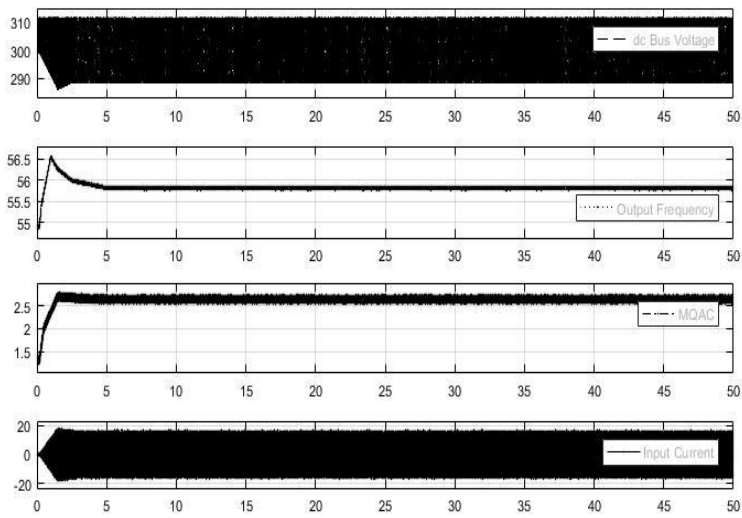

(a)
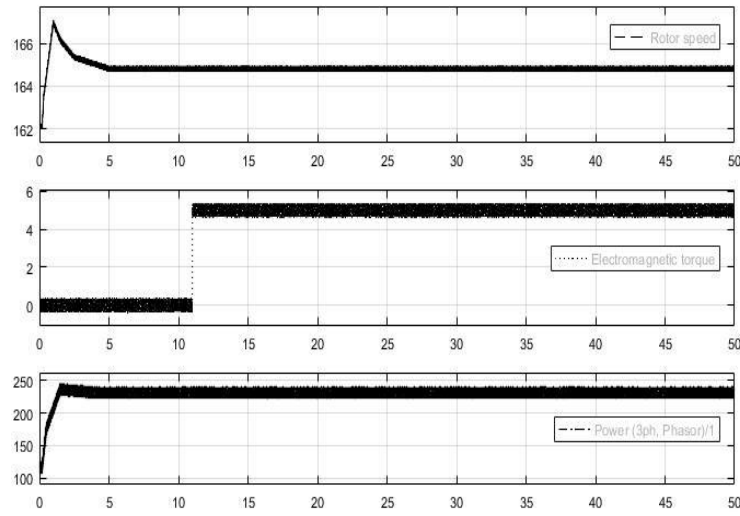

(b)

Figure 9. Test results of proposed MQAC method for frequency fold-back [16] with IQ-Average current method with 50sec (a) output frequency and MQAC (b) speed and torque control 

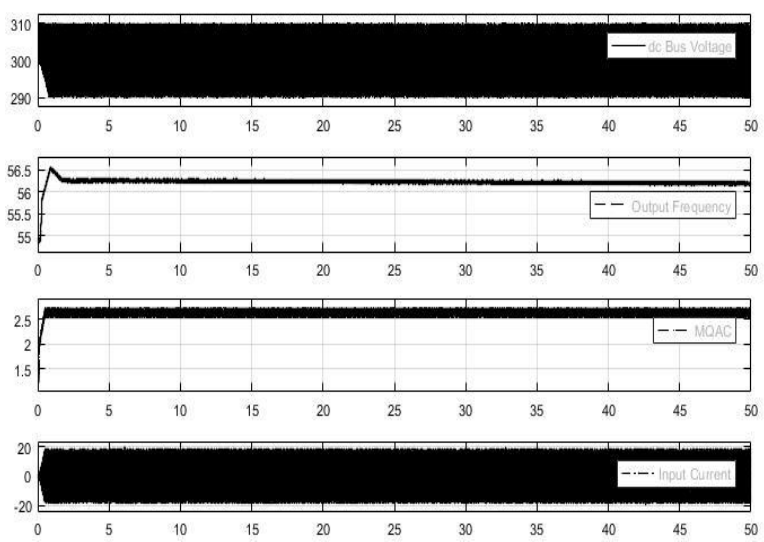

(a)
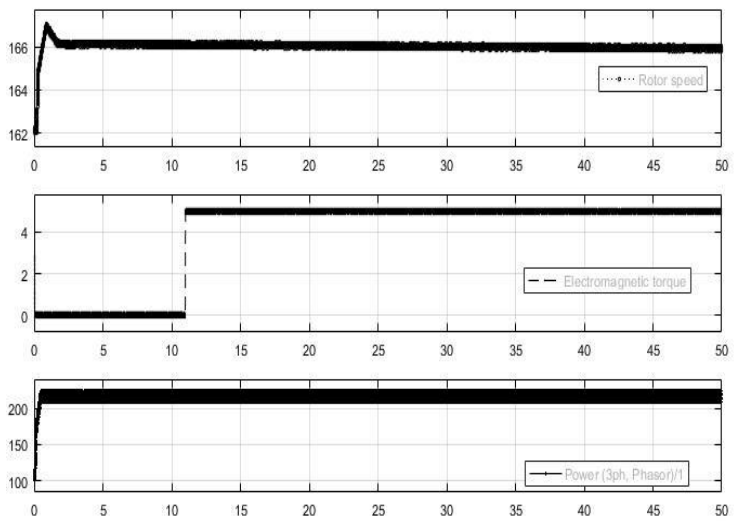

(b)

Figure 10. Test results for the proposed torque ripple control (TRC) method with 50sec
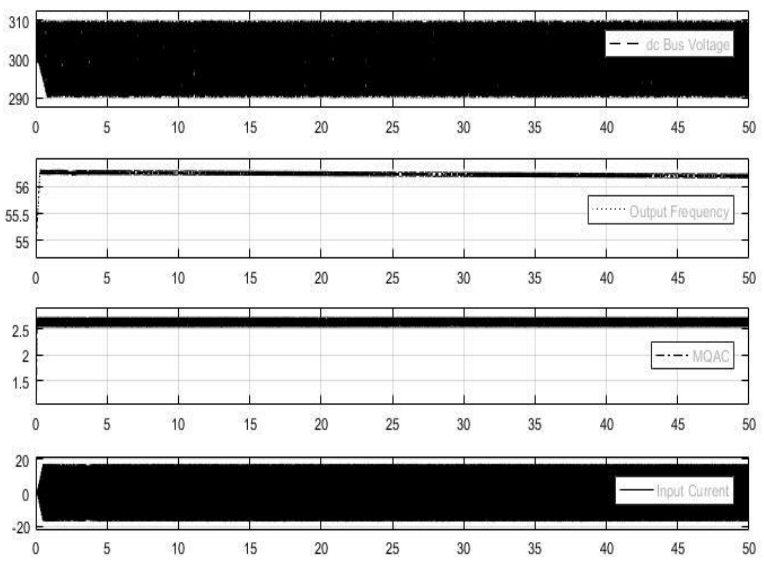

(a)
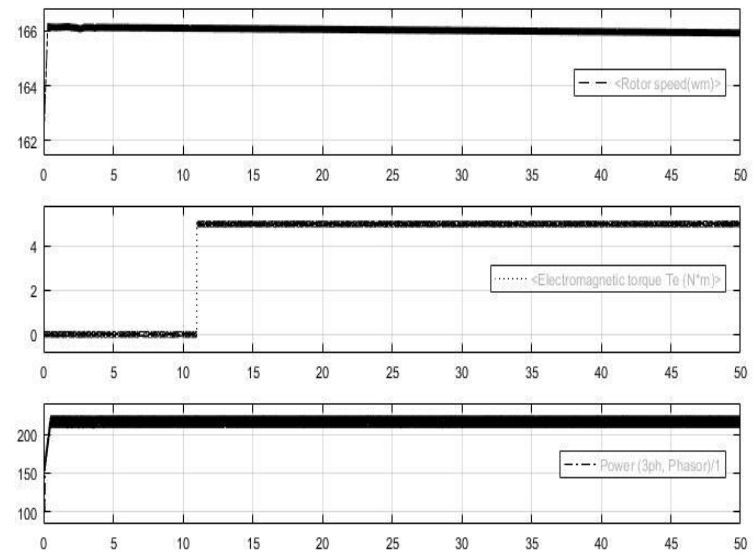

(b)

Figure 11. Test results for the self-tuning PI controller with PSO method for 50sec

In Figure 9, we presented the same scenario with IQ-Average current method for $50 \mathrm{sec}$ time periods, where the ripples have been reduced and obtained steady state performance better over IQ-Ripple current method demonstrated in Figure 8. As we said above the rotor speed and three phase output power depends on the input current as well as the output frequency. When there is a change in input current and output frequency then speed of rotor and three phase output power will alters according to the respective changes. Figure 10 shows that the proposed TRC test results, in which the input current and output frequency obtained the steady state performance lesser over both IQ-Average and IQ-Ripple. We can see that in above figure there are no ripples in input current as well as output frequency and it maintained a steady state value after lesser than 3 sec. Figure 11 shows that the STP-PSO frame work, in which the output frequency and input current steady state values are almost equal to zero. This leads the mitigation of rotor speed and output power, which in results the stress over the loads will be reduced to maximum possible extension. The performance test results of steady state values are dispayed in table II and the best values are quoted in bold face.

Table 2. Test Results for a Practical Pumping Application

\begin{tabular}{cccccc}
\hline Steady State Values & $\begin{array}{c}\mathrm{V}_{\mathrm{dc}} \\
\text { (Peak-to-Peak) }\end{array}$ & $\begin{array}{c}\mathrm{I}_{\text {INPUT }} \\
\text { (Peak-to-Peak) }\end{array}$ & $\begin{array}{c}\mathrm{I}_{\text {INPUT }} \\
\text { (RMS) }\end{array}$ & $\begin{array}{c}\text { Motor Speed } \\
\text { (Per Unit) }\end{array}$ & P $_{\text {OUtPUT }}$ \\
\hline DC bus voltage ripple method [15] & $28.8 \mathrm{~V}$ & $39.9 \mathrm{~A}$ & $5.7 \mathrm{~A}$ & 0.94 & $0.47 \mathrm{hp}$ \\
q-axis ripple current method [16] & $25.3 \mathrm{~V}$ & $34.1 \mathrm{~A}$ & $4.9 \mathrm{~A}$ & 0.86 & $0.37 \mathrm{hp}$ \\
q-axis average current method [16] & $23.5 \mathrm{~V}$ & $30.5 \mathrm{~A}$ & $4.3 \mathrm{~A}$ & 0.81 & $0.31 \mathrm{hp}$ \\
TRC method & $22.5 \mathrm{~V}$ & $28.5 \mathrm{~A}$ & $4.1 \mathrm{~A}$ & 0.8 & $0.3 \mathrm{hp}$ \\
STP-PSO & $21.5 \mathrm{~V}$ & $28 \mathrm{~A}$ & $3.9 \mathrm{~A}$ & 0.75 & $0.29 \mathrm{hp}$ \\
\hline
\end{tabular}




\section{CONCLUSION}

A novel motor q-axis current (M-QAC) with torque ripple control (TRC) of an induction motor and self-tuning PI controller with particle swarm optimization (STP-PSO) implemented for mitigating the stress over induction motor by the torque ripple elimination and controlling. Our proposed approach has an information related to the different parts stresses of the VFD which includes the terminal block and the diodes in the input side, DC bus capacitors, torque ripple, harmonics in the current and active performance for sudden changes in the speed and load. By using the proposed TRC and STP-PSO schemes, the stress over the AC motor and the other components has been mitigated to improve the VFD utilization further effectively. We obtained maximum possible optimized VFD with our proposed approaches. The proposed control strategy is aimed to be utilized as an extra feature as a protection for the drives during the operations of single-phase with the drive's lifetime and reliability has been enhanced in an impressive manner for the same power derating when compared to the drives operating with a protection feature based on dc-busvoltage-ripple.

\section{REFERENCES}

[1] Campbell, Sylvester J. "Solid-State AC Motor Controls", New York: Marcel Dekker, Inc. pp. 79-189, 1987.

[2] Siskind and Charles S. "Electrical Control Systems in Industry", New York: McGraw-Hill, Inc. p. 224, 1963.

[3] NEMA Standards Publication Application Guide for AC Adjustable Speed Drive Systems Rosslyn, VA USA: National Electrical Manufacturers Association (now the Association of Electrical Equipment and Medical Imaging Manufacturers). p. 4, Retrieved Mar 27, 2008.

[4] E. C. dos Santos, et al. "Single- phase to three-phase power converters: State of the art," IEEE Transactions on Power Electronics, vol. 27, no. 5, pp. 2437-2452, May 2012.

[5] M. Lazic, et al., "Designing of multiphase boost converter for hybrid fuel cell/battery power sources," in Paths to Sustainable Energy, J. Nathwani and A. Ng, Eds. Rijeka, Croatia: InTech, Dec. 30, 2010.

[6] Y. Jang and M. M. Jovanic, "A bridgeless PFC boost rectifier with optimized magnetic utilization," IEEE Transactions on Power Electronics, vol. 24, no. 1, pp. 85-93, Jan. 2009.

[7] P. N. Enjeti and A. Rahman, "A new single-phase to three-phase converter with active input current shaping for low cost AC motor drives," IEEE Tranactions on. Industiral Applications, vol. 29, no. 4, pp. 806-813, Jul./Aug. 1993.

[8] T. B. Bashaw and T. A. Lipo, "B4 topology options for operating three phase induction machines on single phase grids," in Proc. of IEEE Applied Power Electronics Conference and Exposition, pp. 1894-1902, Mar. 2005.

[9] P. N. Enjeti, et al., "Economic single-phase to three-phase converter topologies for fixed and variable frequency output," IEEE Transactions on Power Electronics, vol. 8, no. 3, pp. 329-335, Jul. 1993.

[10] D. M. Divan, "A new topology for single UPS systems," in Conference Record of the IEEE Industry Applications Society Annual Meeting, pp. 931-936, 1989.

[11] M. Swamy and C. Guddanti, "An improved single-phase active front end rectifier system for use with three-phase VFDs," in Proc. IEEE Applied Power Electronics Conference and Exposition, pp. 1558-1564, 2014.

[12] B. A. Welchko, et al., "A novel variable frequency three-phase induction motor using only three controlled switches", in IEEE Industry Applications Society Meeting, vol. 37, pp. 1739-1745, Nov./Dec. 2001.

[13] H. Schultz, "Method and system for improving pump efficiency and productivity under power disturbance conditions," u.s. patent 7,330,779 b2, feb. 12, 2008.

[14] T. Sasaki, et al., "pump-protecting device, pump-protecting method, and pumping apparatus," u.s. patent 6,244,825 b1, June 12, 2001.

[15] M. Swamy, "An improved single-phase active front end rectifier system for use with three-phase VFDs," U.S. Patent Applications, Jan. 2013.

[16] Mahesh M. Swamy, et al., "Getting the Most from Variable Frequency Drive: The Optimal Way to Improve Lifetime and Reliability”, IEEE Industry Applications Magazine, vol. 22, no. 6, pp. 57-65, 2016. 